\title{
Antiplatelet Therapy in a Patient with Coronary Artery Disease and Myelodysplastic Syndrome with Thrombocytopenia
}

\author{
Francisco José Fernández-Fernández¹, Eugenia Ameneiros-Lago¹, Cintia Tuñas-Gesto², \\ Inmaculada Gómez-Buela ${ }^{1}$
}

\begin{abstract}
To date, there are no sufficient data to make firm recommendations on the treatment of patients with severe thrombocytopenia who require antiplatelet therapy after experiencing acute coronary syndrome. Therefore, we think that it is important to communicate the experience with individual cases. We report the case of a patient who presented with pericardial effusion causing cardiac tamponade. He had thrombocytopenia associated with myelodysplastic syndrome, and ten weeks before this admission, percutaneous transluminal coronary angioplasty with implantation of drug-eluting stents was performed for non-ST-segment elevation acute coronary syndrome. Platelets in myelodysplastic syndromes are dysfunctional, which exacerbates bleeding from thrombocytopenia, and the management of atherosclerotic cardiovascular disease in these patients is challenging.
\end{abstract}

\section{KEYWORDS}

myelodysplastic syndromes; thrombocytopenia; acute coronary syndrome; antiplatelet therapy; clopidogrel; drug-eluting stents

\section{AUTHOR AFFILIATIONS}

${ }^{1}$ Department of Internal Medicine, Complejo Hospitalario Universitario de Ferrol, Ferrol 15405, Spain

2 Section of Neurology. Complejo Hospitalario Universitario de Ferrol, Ferrol 15405, Spain

* Corresponding author: Department of Internal Medicine, Complejo Hospitalario Universitario de Ferrol, Ferrol 15405, Spain; e-mail: ff.fernandez2@gmail.com

Received: 30 March 2017

Accepted: 23 May 2017

Published online: 5 October 2017

Acta Medica (Hradec Králové) 2017; 60(2): 82-84

https://doi.org/10.14712/18059694.2017.98

(c) 2017 The Authors. This is an open-access article distributed under the terms of the Creative Commons Attribution License (http://creativecommons.org/licenses/by/4.0), which permits unrestricted use, distribution, and reproduction in any medium, provided the original author and source are credited. 


\section{INTRODUCTION}

The safety of antiplatelet therapy in patients who have acute coronary syndrome and thrombocytopenia is unknown, and there are no randomized studies to make firm recommendations on treatment approaches in such patients. Likewise, in patients with thrombocytopenia, the risk of bleeding varies and may depend upon the underlying cause $(1,2)$. Platelets in myelodysplastic syndromes are dysfunctional (3) and, after leukemic transformation and infection, bleeding is the next most common cause of death (4-6). On the other hand, thrombocytopenia itself is not protective and acute coronary syndromes have been reported in patients who have thrombocytopenia that is associated with various disorders (7-9). In the setting of cancer and hematologic malignancies, some smaller sized retrospective studies have shown that aspirin may be beneficial in thrombocytopenic patients experiencing acute coronary syndromes $(10,11)$. Therefore, the management of atherosclerotic cardiovascular disease in patients who have myelodysplastic syndrome with thrombocytopenia is challenging.

We report the case of a 77-year-old man who presented with pericardial effusion causing cardiac tamponade. $\mathrm{He}$ had thrombocytopenia associated with myelodysplastic syndrome, and ten weeks before this admission, percutaneous transluminal coronary angioplasty with implantation of drug-eluting stents was performed for non-ST-segment elevation acute coronary syndrome.

\section{CASE REPORT}

A 77-year-old man was admitted to our Department because of a pericardial effusion causing cardiac tamponade. The patient was a former smoker with a history of hypertension, hyperlypidemia, type 2 diabetes, interstitial lung disease, colon diverticular disease, and adenomatous colonic polyps. Ten weeks before this admission, he had been hospitalized for a non-ST-segment elevation acute coronary syndrome. Coronary angiography showed a $90 \%$ stenosis of the left main trunk, $99 \%$ stenosis of the proximal anterior descending artery, $75 \%$ stenosis of the mid portion of the anterior descending artery and $75 \%$ stenosis of the posterior descending artery. Percutaneous transluminal coronary angioplasty was performed with implantation of drug-eluting stents. On initial testing, the patient had pancytopenia with leukocytes $3.23 \times 10^{9} / 1$, hemoglobin $10.9 \mathrm{~g} / \mathrm{dl}$ and platelets $58 \times 10^{9} / \mathrm{l}$. The presence of platelet clumping was reported in a peripheral blood smear. Ferritin, vitamin B12 and serum folate were normal. A bone marrow study was not performed. The patient was prescribed ticagrelor and acetylsalicylic acid. Two months after being discharged, he was admitted to the Department of Neurology because of decreased visual acuity in the right eye due to ischemic optic neuropathy. During this 2nd hospitalization, the count of platelets ranged from 36 $\times 10^{9} / 1$ to $47 \times 10^{9} / 1$. Peripheral blood smear confirmed the thrombocytopenia without platelet clumping. Tests for human immunodeficiency virus, hepatitis B surface antigen, hepatitis B core antibody, and hepatitis C antibody were negative. IgM antibodies directed against the VCA of Epstein-Barr virus, cytomegalovirus and parvovirus B19 were also negative. Serum angiotensin converting enzyme was normal. In the imaging studies the spleen was of normal size. He was evaluated by a hematologist and was discharged and referred to the outpatient hematology clinic for further investigation. Five days later, the patient was readmitted because of pericardial effusion with cardiac tamponade. $1100 \mathrm{ml}$ of serosanguineous pericardial fluid was drained. Microbiologic studies of the pericardial fluid for bacteria, acid-fast bacteria, and fungus were negative. Cytologic analysis of the pericardial fluid was negative for malignant cells. A bone marrow examination revealed myelodysplastic syndrome (refractory anemia with excess blasts-1) and cytogenetics showed 20q deletion. During this third hospitalization several episodes of epistaxis developed and we decided to discontinue ticagrelor and acetylsalicylic acid, and antiplatelet therapy with clopidogrel alone was initiated. At 12 months follow-up the patient remains well, and there were no further thrombotic complications or significant bleeding episodes, with a platelet count of $31 \times 10^{9} / 1$ to $60 \times 10^{9} / 1$ during this time period. A follow-up echocardiogram showed no recurrence of pericardial effusion, and the Hematology Service indicated that the patient was managed expectantly in order to evaluate the disease tempo.

\section{DISCUSSION}

To date, there are no guidelines on the treatment of patients with thrombocytopenia who require antiplatelet therapy after experiencing acute coronary syndrome. Therefore, it is important to communicate the experience with individual cases. In patients with thrombocytopenia, the risk of bleeding varies and may depend upon the underlying cause $(1,2)$. Younger circulating platelets are larger and more hemostatically active. For example, patients with primary immune thrombocytopenia have younger circulating platelets and, consequently, less severe bleeding symptoms than patients with a similar degree of thrombocytopenia due to bone marrow failure, whose platelets tend to be older and hypoactive $(1,3)$. Platelets in myelodysplastic syndromes often express abnormally low levels of procoagulant cell surface markers or lack intracellular granules, which exacerbates bleeding from thrombocytopenia (4-6).

The patient had a history of iron-deficiency anemia due to gastrointestinal blood losses, and deletion 20q on cytogenetic analysis. Thrombocytopenia is the most frequent cytopenia in myelodysplastic syndrome patients presenting with deletion $20 q$ on cytogenetic analysis and, in these cases, the dysplasia is often subtle (12). Both factors could decrease the suspicion of the hematologic process, and drug-eluting stents were implanted for the multivessel revascularization of the patient with complex coronary anatomy. With respect to the pericardial effusion, a serositis as autoimmune manifestation of myelodysplastic syndrome has rarely been reported $(13,14)$. In these cases, the pericardial effusion usually responds to treatment with corticosteroids and this origin was unlikely in our patient. Likewise, 
the performed studies and evolution ruled out the possibility of pericardial effusion due to infiltration of blast cells.

In summary, our patient, with drug-eluting stents, had a high thrombotic and hemorrhagic risk. There was a delay in establishing the diagnosis of myelodysplastic syndrome, and after 10 weeks with dual antiplatelet therapy, clopidogrel alone was effective with a platelet count of 31 $\times 10^{9} / 1$ to $60 \times 10^{9} / 1$.

\section{REFERENCES}

1. Rinder HM, Tracey JB, Recht M, et al. Differences in platelet alpha-granule release between normals and immune thrombocytopenic patients and between young and old platelets. Thromb Haemost 1998; 80: 457-62.

2. Fernández-Fernández FJ. Acute coronary syndrome in patients with thrombocytopenia. Rev Esp Cardiol (Engl Ed.) 2017; 70: 682.

3. Manoharan A, Brighton T, Gemmell R, Lopez K, Moran S, Kyle P. Platelet dysfunction in myelodysplastic syndromes: a clinicopathological study. Int J Hematol 2002; 76: 272-8.

4. Kantarjian H, Giles F, List A, et al. The incidence and impact of thrombocytopenia in myelodysplastic syndromes. Cancer 2007; 109: 1705-14.

5. Nachtkamp K, Stark R, Strupp C, et al. Causes of death in 2877 patients with myelodysplastic syndromes. Ann Hematol 2016; 95: 937-44.
6. Steensma DP. Myelodysplastic syndromes: diagnosis and treatment. Mayo Clin Proc 2015; 90: 969-83.

7. Fruchter O, Blich M, Jacob G. Fatal acute myocardial infarction during severe thrombocytopenia in a patient with idiopathic thrombocytopenic purpura. Am J Med Sci 2002; 323: 279-80.

8. Hasper D, Schrage D, Niesporek S, Knollmann F, Barckow D, Oppert M. Extensive coronary thrombosis in thrombotic-thrombocytopenic purpura. Int J Cardiol 2006; 106: 407-9.

9. Bermejo N, Sigüenza R, Ibáñez F. Management of primary immune thrombocytopenia with eltrombopag in a patient with recent acute coronary syndrome. Rev Esp Cardiol (Engl Ed) 2017; 70: 56-7.

10. Feher A, Kampaktsis PN, Parameswaran R, Stein EM, Steingart R, Gupta D. Aspirin is associated with improved survival in severely thrombocytopenic cancer patients with acute myocardial infarction. Oncologist 2017; 22: 213-21.

11. Sarkiss MG, Yusuf SW, Warneke CL, et al. Impact of aspirin therapy in cancer patients with thrombocytopenia and acute coronary syndromes. Cancer 2007; 109: 621-7.

12. Gupta R, Soupir CP, Johari V, Hasserjian RP. Myelodysplastic syndrome with isolated deletion of chromosome 20q: an indolent disease with minimal morphological dysplasia and frequent thrombocytopenic presentation. Br J Haematol 2007; 139: 265-8.

13. Fernández-Sojo J, Vives S, Oliveras Vilà T, Ribera JM. Exudative pericardial effusion and oligoarthritis in a patient newly diagnosed with myelodysplastic syndrome. Med Clin (Barc) 2014; 143: 43-4.

14. Choi J-H, Ahn M-J, Park Y-W, Oh HS, Lee YY, Kim IS. A case of erythema nodosum and serositis associated with myelodysplastic syndrome. Korean J Intern Med 2005; 20: 177-9. 